\title{
EVOLUÇÃO NEUROLÓGICA E ELETRENCEFALOGRÁFICA EM CRIANÇAS APOS MENINGENCEFALITES PURULENTAS
}

\author{
TEREZINHA BRAGA MONTELLI* \\ MARIA VALERIANA MOURA RIBEIRO ** \\ RUBENS MOURA RIBEIRO ** \\ MARIO CARNEIRO LEAO RIBEIRO ***
}

Embora a utilização de antibióticos tenha reduzido consideravelmente a mortalidade ocasionada pelas meningencefalites purulentas, as sequelas neurológicas, quer intensas e incapacitantes, quer de natureza diversa como as que ocasionam alteraçōes do comportamento, são citadas com frequência na literatura $\mathbf{1 , 2 , 3 , 5 , 6 , 7}$. Assim a preocupação dos que tem a responsabilidade de decidir sobre as várias opções terapêuticas possíveis, deve voltar-se também para as consequências determinadas pela doença nos pacientes.

Porém, poucos são os elementos de que dispomos para procurar reduzir a intensidade e a gravidade das sequelas, porque os mecanismos fisiopatológicos que determinam o maior ou menor comprometimento do sistema nervoso central (SNC) são pouco conhecidos '. Este aspecto torna-se ainda mais complexo quando se trata de estudar os efeitos das agressões infecciosas ao SNC en? crianças, nas quais a fase de maturação cerebral em que se encontram é muito importante. Fitzharding e col. ${ }^{2}$ relatam, em trabalho prospectivo sobre meningencefalites purulentas em recém-nascidos, que maior proporção de crianças com infecções por bactérias gram-negativas apresentaram Q.I. abaixo da média; por outro lado, maior número de crianças que tiveram infeccōes por hactérias grampositivas apresentaram Q.I dentro das variações normais.

Este fato poderia estar relacionado à velocidade de resposta à terapêutica anti-microbiana. Níveis constantes de antibióticos no líquido cefalorraqueano (LCR) várias vezes maiores que as concentrações inibitórias mínimas das bactérias patogênicas, parecem ser necessários para uma esterização rápida. Isto é facilmente conseguido quando se administra penicilina ou ampicilina por via parenteral, parém não o é quando se administra aminoglicosídeos*.

Existe grande dificuldade em se estabelecer as relações entre a intensidade. as variaçōes das manifestações neurológicas na fase aguda e o prognóstico da evolução ${ }^{\circ}$. A duração da doença $e$ a idade em que ocorre a meningencefalite poderiam ser variáveis importantes para a evolução neurológica. Será de grande

\footnotetext{
* Departamento de Neurologia e Psiquiatria da Faculdade de Ciéncias Médicas e Biológicas de Botucatu; **Departamento de Neuropsiquiatria e Psicologia Médica da Faculdade de Medicina de Ribeirão Preto: ***Departamento de Estatística da Faculdade de Ciências Médicas e Biológicas de Botucatiu.
} 
utilidade a identificação de manifestações neurológicas ou de alteraçĩes nos exames subsidiários que ajudem a decidir sobre, por exemplo, a necessidade de administração intra-tecal ou intra-ventricular de antibióticos, mesmo quando não existe risco de morte. A única forma de obtermos informacões sobre estes aspectos é mediante seguimento prolongado de pacientes.

O objetiva deste trabalho é procurar estabelecer correlações entre alguns elementos da fase aguda da doença em crianças e as sequelas neurológicas. mediante o acompanhamento clínico e eletrencefalográfico por vários anos.

\section{MATERIAL}

O material é constitufdo por 20 crianças, cujas idades mostramos na tabeia 1 . internadas no Hospital das clínicas da Faculdade de Medicina de Ribeiråo Preto, na enfermaria de Moléstias Infecciosas, com meningencefalite purulenta como doença primária, entre os anos de 1963-1967. Foram excluidos pacientes que, juntamente com 0 processo meningencefalítico, apresentassem encefalopatia infantil, hidrocefalia, malformações raquimedulares ou desnutriçăo grave

\begin{tabular}{rrrrrr}
\multicolumn{3}{c}{ Idade } & No de casos \\
\hline 1 & a & 6 & meses & 6 \\
6 & a & 12 & meses & 4 \\
1 & a & 2 & anos & 1 \\
2 & a & 3 & anos & 3 \\
3 & a & 4 & anos & 0 \\
4 & a & 5 & anos & 1 \\
5 & a & 6 & anos & 1 \\
6 & a & 7 & anos & 2 \\
7 & a & 11 & anos & 0 \\
1.1 & a & 12 & anos & 2 \\
\hline
\end{tabular}

Tabela 1 - Distribuicão dos 20 pacientes de acordo com a idarte.

\section{METODOS}

O diagnóstico clínico foi confírmado pelo exame citológico e bioquímico do LCR. A identificaçăo do agente etiológico fol felta mediante cultura: Neisseria meningitidis em 3 pacientes, Hemophilus influenzae em um; em 16 pacientes a cultura foi negatjva.

Durante a fase aguda, a avaliação clínica e neurológica foi realizada diariamente e os exames de LCR repetidos cada 10 dias. As crianças foram submetidas a exames eletrencefalográficos (EEG), segundo a técnica recomendada pela International Federation for Electroencephalography and Clinical Neurophysiology.

A evoluçăo dos casos foi estudada longitudinalmente sob os aspectos neurológico, eletrencefalográfico e de desenvolvimento neuropsicomotor (testes de Gesell) ou inental (teste de Raven). Estes exames foram realizados entre 6 meses e 3 anos após a alta hospitalar. Os resultados dos testes são expostos sob forma de quociente de desenvolvimento (Q.D.), para o teste de Gesell e quociente intelectual (Q.I.), para o teste de Raven (Idade mental mediana/idade cronológica $\times 100$ ). A idade mediana é a idade correspondente ao número de pontos obtidos na coluna do Percentil 50. 
Os grupos controle foram procurados entre crianças de nível sócio-econômico A cultural o maís próximo possivel dos pacientes internados em Hospital Universitário, que só atende às classes mais desfavorecidas. Assim, para o grupo de 1 mês - 3 anos, estudamos 40 crianças do ambulatório de Puericultura do Departamento de Pediatria do mesmo hospital, nas quais o desenvolvimento neunopsicomotor foi avaliado pelo teste de Gesell.

Para o estudo comparativo do desenvolvimento mental pelo teste de Raven, escolhemos como controles 30 crianças de 6 a 12 anos de idade, do Grupo Escolar Rural Monte Alegre.

Metodologia de analise - Quocientes de desenvolvimento e intelectuais: as comparações entre médias populacionais foram feitas mediante teste bicaudal pela estatística de Mann Whitney, utilizando-se a aproximaçăo pela normal, quando possivel. As correlações entre Q.D., idade, níveis de proteína do LCR e tempo de normalizaçăo do LCR foram estudadas pela estatística de Spearman. Nas provas de significância adn. tou-se o nivel $\alpha=0,05$.

\section{RESULTADOS E COMENTARIOS}

A figura 1 mostra os sintomas e sinais clínicos. em ordem decrescente de frequência, por ocasião da admissão hospitalar, ao primeiro exame neurológico.

Estes resultados são diferentes dos obtidos por Lefèvre e col. ${ }^{3}$ durante surto epidêmico de meningite meningocócica em São Paulo. Chama a atenção a menor incidência de coma (4\%), de convulsões (13\%) e de alterações de nervos cra-

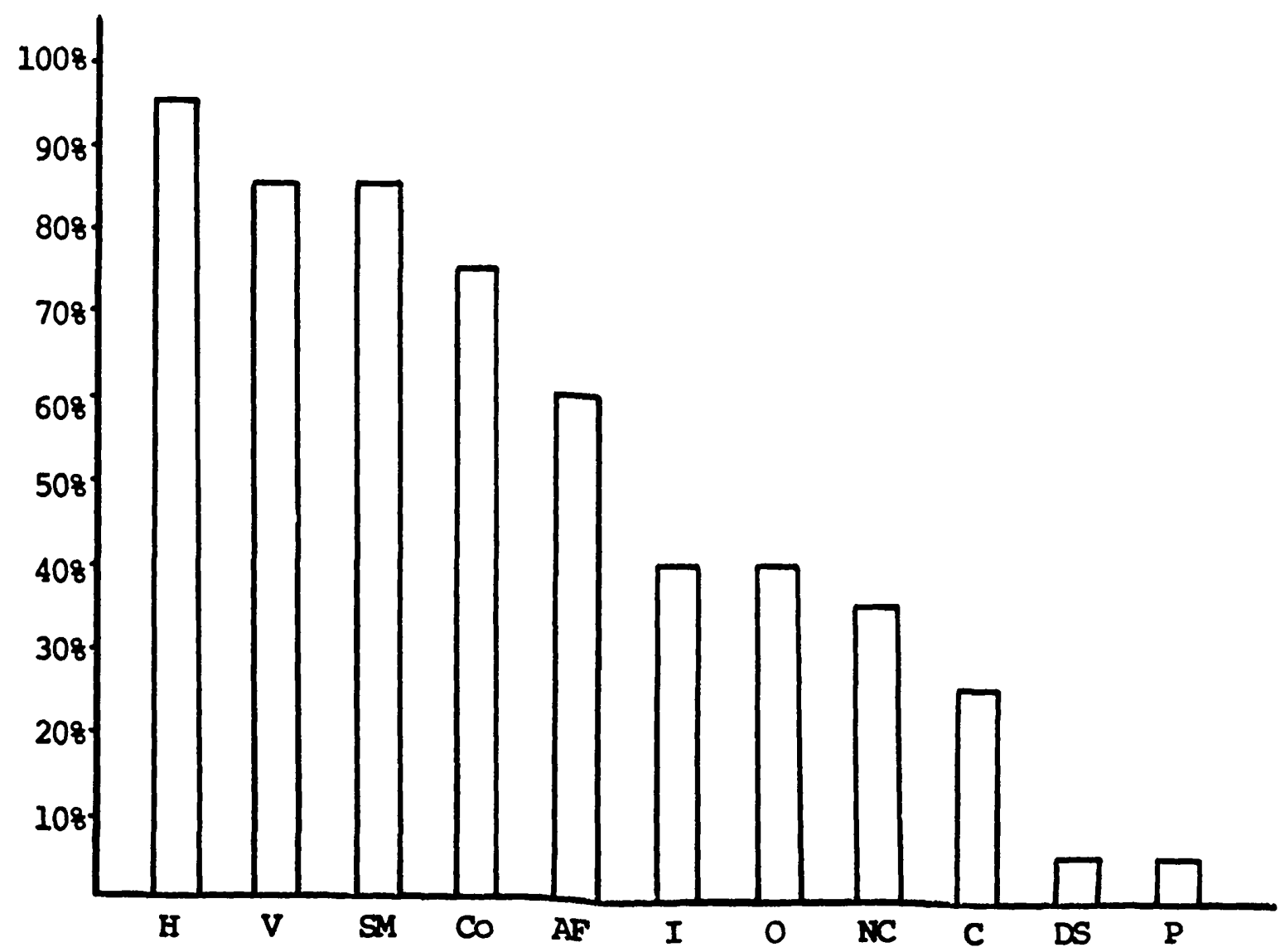

E'ig. 1 - Sintomas e sinais clinicos por ocasiăo da admissăo. Legenda: $H=$ hipertermia; $V=$ vomitos; $S M=$ sinais menirgeos; Co $=$ convulsסes; $A F=$ abaulamento de fontanelas; I irritabilidade; $O=$ obnubilacå; $N C=$ alterąbes de nervos cranianos (39, 69 $\left.\mathrm{e} 7^{\circ}\right) ; C=$ coma: $\mathrm{DS}=$ disjunç̋o de suturas; $P=$ paresias ou plegias. 
nianos (9\%) encontradas por Lefèvre e colaboradores. Entretanto, esta casuistica refere-se a casos selecionados, com "atendimento muito satisfatório" e nos quais o diagnóstico foi precoce, além da meningite dever-se a etiologia única. Em época de endemia, o diagnóstico é mais frequentemente tardio.

A figura 2 mostra os sintomas e sinais clínicos após a alta hospitalar, com intervalo que variou de 6 meses a 3 anos, conforme o caso. As alteracões neurológicas consistem em tetraparesia, hemiparesia, microcefalia, hidrocefalia e comprometimento dos nervos cranianos.

As convulsões na maior parte dos casos são parciais, com ou sem generalização secundária (8 casos). Entretanto, 4 crianças apresentaram encefalonatias epiléticas graves (sindromes de West e de Lennox).

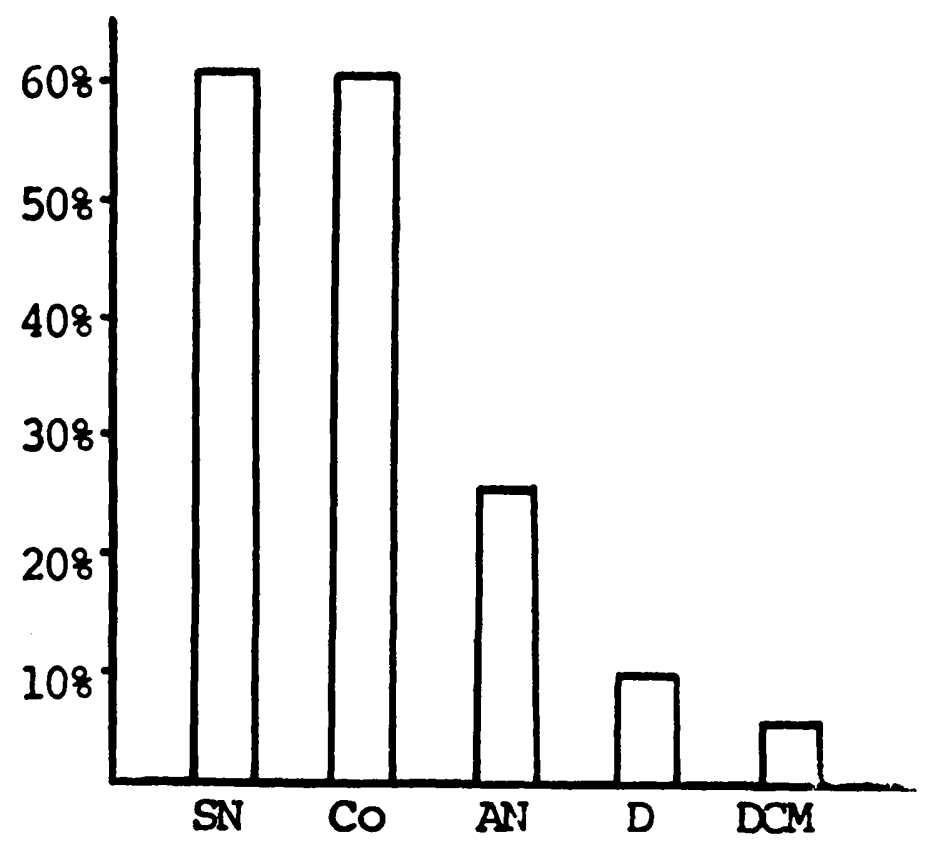

Fig. 2 - Resultados do exame neurologico, 6 meses a 3 arios apbs a alta hospitalar. Legenda: $\mathrm{SN}=$ semiologia normal; Co = convulsoes; $A N=$ alteraçes neurologicas; $D=$ dislexia e/ou disgrafia; DCM = disfunç̃o cerebral minima.

A figura 3 mostra os resultados dos eletrencefalogramas realizados durante a fase aguda da doença e durante o seguimento ulterior. Observamos novamente resultados bastantes diferentes dos de Lefèvre e col. ${ }^{\text {, }}$, que encontraram apenas $5 \%$ de traçados anormais.

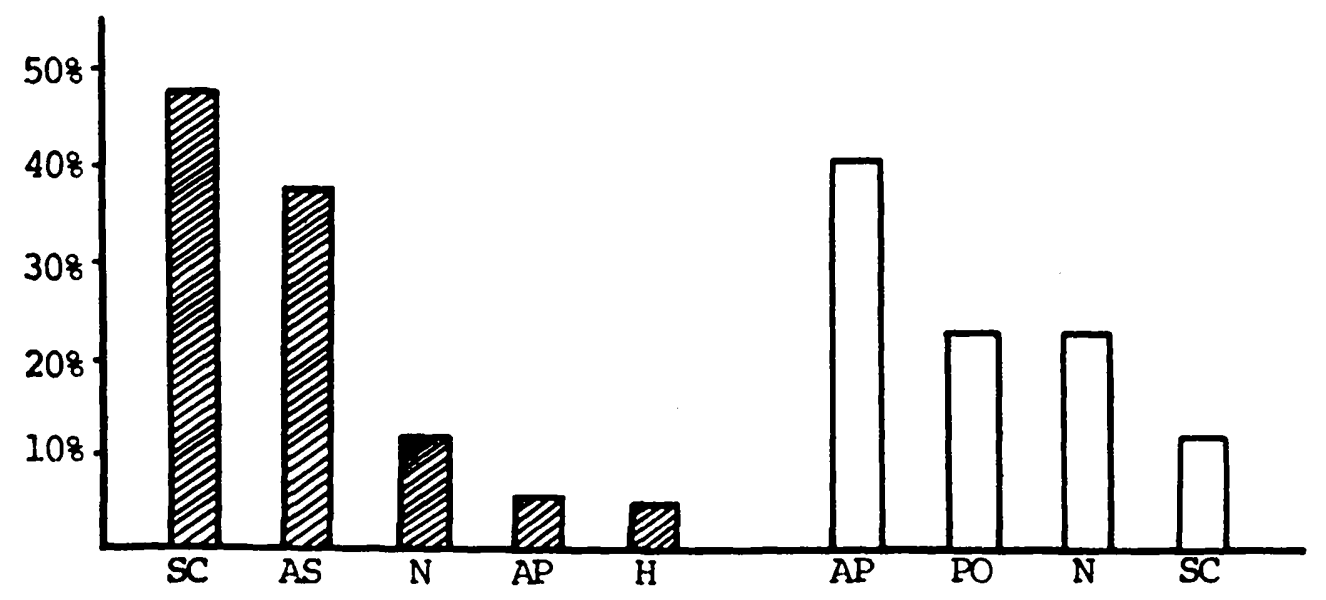

Fig. 3 - Resultados dos eletrencefalogramas: em colunas riscadas, durante a fase aguda; em colurais claras, 6 meses a 3 anos ap68 a fase aguda. Legenda: $\mathrm{SC}=$ sofrimento cerebral; $A S=$ alteraçбes paroxisticas $e$ sofrimento cerebral: $N=$ normais; $A P=$ alteracoses paroxisticas; $H=$ hipsarritmia; $P O=$ pontas-ondas lentas. 
$\mathrm{Na}$ fase aguda da doença, já encontramos a instalação da sindrome de West em uma criança de 4 meses. Durante os seguimentos ulteriores, surgiram 3 casos de síndromes de Lennox em crianças que tiveram meningencefalite com 5, 9 e 25 meses. Seus EEGs da fase aguda mostraram sofrimento cerebral com ou sem alterações paroxísticas ( 2 casos) ou apenas alterações paroxísticas (1 caso). Três destas crianças foram internadas em estado de coma e uma com crise convulsiva.

A tabela 2 mostra as medianas e as amplitudes totais dos Q.D. de crianças que contrairam meningencefalites entre 1 mês a 2 anos e meio de idade, comparadas às crianças normais. Nos 14 casos do grupo experimental estão incluídas as 4 crianças que adquiriram encefalopatias epiléticas, patologias que por si só ocasionam intenso compromentimento no desenvolvimento neuro-psico-motor. A análise da influência destes casos, é feita na tabela 3. Vemos que as medianas dos Q.D. do grupo 2 são bem mais altas que as do grupo 3, porém a grande diferença estatística do grupo 2 com o grupo controle permanece. As crianças que tiveram encafolapatias epiléticas após a meningencefalite apresentaram retardo de desenvolvimento neuro-psico-motor mais intenso, conforme demonstra a análise.

Salientamos a semelhança de nossos resultados com os de Sell e col. ${ }^{7}$, que estudaram 46 crianças que tiveram meningencefalites bacterianas antes dos 3 anos de idade, mediante testes psicológicos, quando estas atingiram a idade escolar. Seus resultados foram comparados com os de 2 grupos controles, selecionados por variáveis emparelhadas (irmão de idade próxima não meningítico ou colega de classe com mesma idade, sexo e nível social). Os autores concluem que "os sobreviventes da doença tiveram o SNC lesado" em vista das ciferenças de seus Q.I. em relação aos dos 2 grupos controles.

Procuramos ainda determinar a correlação entre o tempo de infecção estimado mediante o tempo de normalização do LCR durante a internação e o Q.D. $O$ tempo de normalização do $L C R$ variou de 10 a 50 dias, sendo a mediana de 21 dias, O coeficiente de correlação* de Spearman entre o tempo de normalização do LCR e o Q.D. de crianças que contrairam a infecção com menos de 2 anos e meio, nos forneceu os seguintes resultados: $r s=-0,166$ (n.s.); nível crítico $=-0,06: \alpha=0,05$.

Ao contrário do que se poderia esperar, não encontramos correlação entre o tempo de normalização do LCR e o Q.D. É preciso lembrar entretanto, de uma variável muito importante que pode influir neste resultado e que não analisamos: o tempo de duração da doença antes da terapêutica. E difícil determiná-lo com exatidão pela anamnese, pois frequentemente a meningencefalite se segue a outros infecciosos (amigdalites, otites).

Fitzharding e col. 2 encontraram associação entre os níveis de proteina do LCR, mortalidade e sequelas neurológicas em 37 casos de meningite neonatal; estes autores comentam que “o pobre prognóstico associado aos altos níveis de

* As correlações foram analisadas com apenas 10 casos, excluindo-se os 4 de ence.. falopatias epiléticas. 


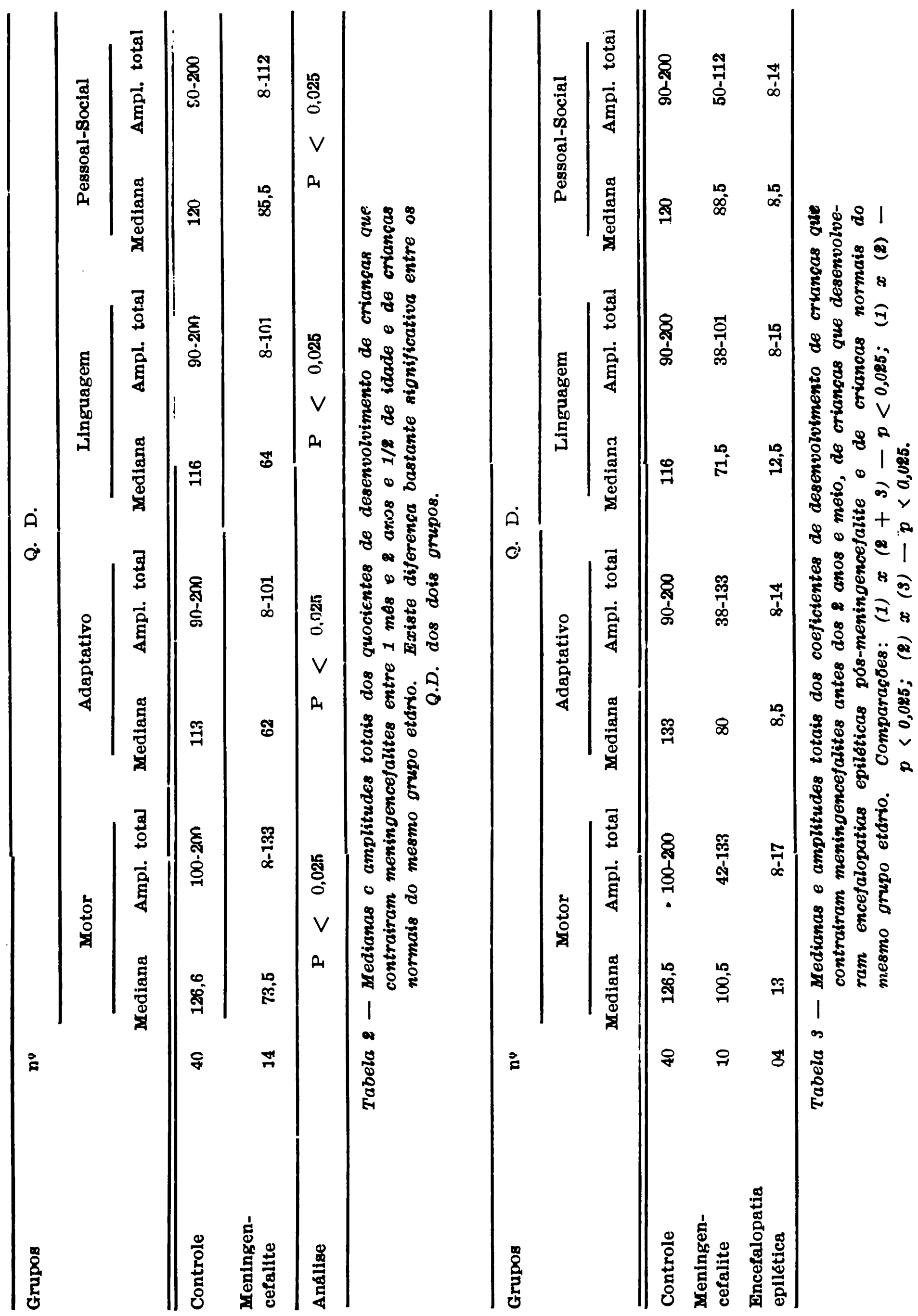


proteina no LCR pode ser explicada por refletir o grau de lesão celular no SNC" e que "os niveis iniciais de proteina no $L C R$, em casos de meningite neonatal, podem ser preditivos em relação ao desenvolvimento ulterior".

$O$ coeficiente de correlação de Spearman entre os niveis de proteina do primeiro LCR e o Q.D. de crianças que contrairam a infecção com menos de 2 anos e meio, nos forneceu os seguintes valores: rs $=0,17$ (n.s.); nivel crítico $=0,48 \alpha=0,05$.

Ao contrário de Fitzharding e col. 2 , não encontramos correlação entre os niveis de proteina do LCR e desenvolvimento neuropsicomotor. Entretanto, considerando-se a grande importância de contarmos durante a fase aguda com algum parâmetro que indique o prognóstico, seria interessante procurarmos melhores esclarecimentos sobre este aspecto, não só em relação às proteinas totais, como também suas frações, mediante eletroforese.

Estas crianças tinham idades que variavam de 1 mês a 2 anos e meio. Procuramos esclarecer se existe correlação entre as idades em cue contrairam a doença e o Q.D., obtendo o seguinte cceficiente de correlação de Spearrman entre as idades das crianças e o Q.D.: $r s=0,48$ (n.s.); nível crítico $=0,56$ : $\alpha=0,05$.

Embura a análise não indique correlação entre estes fatores, chama a atenção a proximidade entre a estatística calculada $(0,48)$ e o valor crítico $(0,56)$. E possível que se venha a concluir pela existência desta correlação com o aumento da casuistica.

$\mathrm{Na}$ tabela 4 apresentamos os resultados dos Q.I. das crianças que tiveram meningencefalite em idade compreendida entre 4 e 12 anos, examinadas 1 a 3 anos após a infecção. Podemos nbservar que não existe diferença entre os Q.I. dos dois grupos estudados.

Dos resultados apresentados concluimos que as alterações do desenvolvimento neuropsicomotor ocorrem com maior frequência em crianças que tem meningencefalite antes dos 2 anos $\mathrm{e}$ meio de idade. Este fato vem demonstrar que para as meningencefalites também se pode aplicar o conceito geral em Neuro-Pediatria, de que tanto piores são as sequelas quanto mais precoce for a agressão ao SNC.

\begin{tabular}{lccc}
\hline Grupos & $\mathrm{n}^{9}$ & \multicolumn{3}{c}{ Q.I. } & \\
\cline { 2 - 4 } & & Medianas & Amplitudes totais \\
\hline $\begin{array}{l}\text { Controle } \\
\begin{array}{l}\text { Meningen- } \\
\text { cefalites }\end{array}\end{array}$ & 30 & 87,5 & $57.8-133$ \\
Análise & 06 & 78 & $76-80$ \\
& $\mathrm{P}>0,05$ & & \\
\hline
\end{tabular}


RESUMO

Foram estudadas 20 crianças internadas com meningencefalite purulenta no Hospital das Clínicas da Faculdade de Medicina de Ribeirão Preto, entre os anos de 1963 e 1967, as quais foram ulteriormente submetidas a estudo prospectivo clínico neurológico, eletrencefalográfico, determinação do quociente de desenvolvimento (teste de Gesell) e do Q.I. (teste de Raven). A duração do seguimente variou de 6 meses a 3 anos, conforme o caso. $O$ quociente de desenvolvimento de crianças que tiveram meningencefalites até os 2 anos e meio de idade foi significativamente menor que o de crianças controles do mesmo grupo etário e classe social.

Não existe correlação entre o Q.D. dessas crianças com os niveis de proteina do LCR ou com o tempo de normalização do LCR. Entretanto, salientamus a possibilidade de se concluir pela correlação entre o Q.D. e a idade em que ocorreu a doença quando maior número de pacientes forem estudados.

Não existe diferença entre os Q.I. de crianças que tiveram meningencefalites após os 4 anos de idade e os de crianças controles, também seleciomadas por grupo etário e classe social

SUMMARY

Neurological and electroencephalographic prospective study' in ihildren u'tth hacterial meningitis.

Twenty children with meningitis diagnosed in the Hospital das Clinicas da Faculdade de Medicina de Ribeirão Preto between 1963 and 1967 were available for prospective study; each was submited to neurological and electroencephalographyc examination, D.Q. (Gesell) and I.Q. (Raven) tests. Patients were followed from 6 months to 3 years after the acute phase of the disease.

There is statistically significant difference between the D.Q. of post-meningitic children and the D.Q. of non meningitic controls of same sucial class and ages, when the onset of illness was before 30 months of age.

No statistically significant correlation was found between the D.Q. and the patient's lenght of hospitalization or the first cerebrospinal fluid protein level. There is a possibility that significant correlation betwenn the D.Q. and age at onset of illness may be observed by studying a larger number of patients.

No statistically significant difference was found between the I.Q. of postmeningitic children and controls when the onset of illness was after age 4.

\section{REFERENCIAS}

1. DODGE, P.R. \& SWARTZ, M. N. - Bacterial meningitis: a review of selected aspects. New Eng. J. Med. 272:1003, 1965.

2. FITZHARDINGE, P. M.; KAZEMI, M.; RAMSAY, M. \& STERN, L. - Long-term qequelae of neonatal meningitis. Develop. Med. Child. Neurol. 16:3, 1974. 
3. LEFEVRE, A. B.; ALMEIDA, I. J. M.; SANTOS, I. ; ELKIS, L. C.; PAZINATO Jr., M.; PAREDES NETOS, M. A.; PINTO, M. C. B.; VALENTE, M. I.; GUIMARAES, M. L. P.; GROSSMAN, R. M.; DEL PORTO, R.; GAZAL, S.; CYPEL, \& GOES, S. L. - Estudo clínico de 78 casos de meningite meningocócica em crianças. Rev. Bras. Def. Mental 10:109, 1975.

4. McCRAKEN Jr., G. H. - The rate of bacteriologic response to antimicrobial therapy in neonatal meningitis. Amer. J. Dis. Child. 123:547, 1972.

5. McDONALD, R. - Purulent meningitis in newborn babies: observations and comments based on a series of 82 patients. Clin. Pediatr. 11:450, 1972.

6. MOURA RIBEIRO. M. V. L. - Meningencefalites purulentas em crianças: estudo clínico e eletrencefalográfico evolutivo. Tese. Faculdade de Medicina de Ribeirão Preto, 1971.

7. SELL, S. H. W.: WEBB, W. W.; PATE, J. E. \& DOYNE, E. O. - Psychological sequelae to bacterial meningitis: two controlled studies. Pediatrics 49:212. 1972

Departamento de Neurologia e Psiquiatria - Fraculdade de Ciências Médicas a Biologicas - 186reo Botucatu, SP - Brasil. 